\title{
ARCHITECTURE OF CREATIVE BECOMINGS: SOU FUJIMOTO Željka PJEŠIVAC*
}

Received: 09.11.2019; Final Text: 17.05.2021

Keywords: (Post-)structuralism; becoming; diffractive reading; spaces in between; Sou Fujimoto's architecture.

1. As Simone Brott states: "The affair between Guattari and Deleuze and the New Wave began long before Guattari's stay in Japan during the 1980s. Deleuze and Guattari had already been in circulation in Japan, via the translation activity surrounding Anti-Oedipus, from as early as the 1970s. Individual essays from Anti-Oedipus and Mille plateaux were all available in Japanese by the early 1980s, before the books were translated into English in their entirety" (Brott, 2011, 75-6).

2. This movement arose directly from a linguistic structuralist theory and it adopted its several key characteristics: (i) understanding a structure (of space, architecture) as a closed concept; (ii) understanding a sign as a relationship between signifier and signified (in Saussure's understanding of these terms), or meaning as a closed system of thought (architecture as a self-referential system of language); (iii) favoring a priori relations among phenomena and their constancies, and systems into which these relations enter, rather than the nature of phenomena themselves; (iv) privileging a dualistic structure of thought (inside-outside, space-body, form-matter, matter-discourse, architecture-landscape, etc); (v) rejection of transcendental or semantic dimension in favor of formal or syntactic dimension and (vi) a-contextuality (that is, the independence of the object from the environment and the wider, changeable urban and social context (primarily restricting the material entity of architecture to a specific social activity))

\section{TOWARD A PHILOSOPHY OF “BECOMING” IN JAPANESE CONTEMPORARY ARCHITECTURE}

The influence of post-structuralist theoretical thinking of Western philosophy, especially the philosophy of Gilles Deleuze and Felix Guattari, on Japanese thinkers and architects began in the 1970s, primarily with the appearance of the Japanese New Wave in architecture (1). The Japanese New Wave in architecture emerged as a critique of structuralist theoretical thought, whose one of the most prominent representatives in Japan was Kenzo Tange (1913-2005). "Kenzo Tange made a radical rupture with the simplistic aspects of international functionalism [Modern Movement] in the 1960s by establishing a Structuralist movement (2) in Japanese architecture and urbanism" (Guattari, 2015, 77). As a reaction to Tange's Structuralism, in Japan, movements such as Metabolism (which makes a step toward a more flexible structure of space, inspired by mass production and industrialization) and Contextualism (which plays with inversions of inside-outside, object-urban and natural environment) appeared during the 1960s, but they remained in the domain of the structuralist theoretical thought. The decisive step beyond structuralist theoretical thinking occurred only in the 1970s, with the emergence of a new form of movement - pluralism - within which the Japanese New Wave appeared.

The New Wave is a name which is, as Guttari $(2015,78)$ states:

"[applied quite arbitrarily to the most inventive Japanese architects of the current generation], given that their diversity is so huge. But it would be even more imprudent to group this generation under the banner of 'postmodernism' since they have fortunately escaped the superficial and eclectic opportunism that generally applies to this qualification in the United States and Europe. [...] Not only have they each strived to develop their own personality; they have each followed the evolution and mutations that traverse their own processes of creation. By always refusing such systematic labeling [... it is possible to] identify, in these architects, some evolutionary becomings that develop very naturally by avoiding all functionalist frameworks, exigencies of context, or even humanist cultural references." 
3. The philosophy of becoming, according to Deleuze and Guattari, is related to the philosophy of changes, processes and transformations, the philosophy of continuous production of differences immanent within the constitution of events, whether physical or otherwise. According to Deleuze and Guattari: "Becoming is the pure movement evident in changes between particular events. This is not to say that becoming represents a phase between two states, or a range of terms or states through which something might pass on its journey to another state. Rather than a product, final or interim, becoming is the very dynamism of change, situated between heterogeneous terms and tending towards no particular goal or end-state.[...] becoming is neither merely an attribute of, nor an intermediary between events, but a characteristic of the very production of events" (Stagoll, 2005, 21-2). It is therefore a view that deviates from Western rationalism, that is, which subjugates any Platonic theory of the privilege of the eternal and unchangeable identities, essences, ideas, forms and beings.

4. For more information see "The Architectural Machines of Shin Takamatsu" (Guattari, 2015, 78-9).

5. Nirvana is according to Buddhist teaching "a state of absence in which the complete cessation of psychic complexes - desire, hatred, attachment - is reached, and in which all feelings, passions, conceptions, all endeavors and finally the whole of consciousness come to an end; or, as Dale Saunders writes, it is a state of a person reposing on himself, withdrawn from the stress and movement of phenomena" (Bognar, 1985, 27). Nirvana is the ultimate goal of Buddhist teaching, not an eternal life, that is, the domain of nothingness, or the Great Void (Bognar, 1985, 27).
Namely, the philosophy of the Japanese New Wave in architecture is very close to the French-based post-structuralist theoretical thought, especially to Gilles Deleuze's and Félix Guattari's studies. In opposition to its predecessors, architects of the Japanese New Wave return to the Japanese Oriental tradition of non-dualistic thinking, interpreting it in a new way by building specific and diverse aspects of architecture of creative becomings (3). Thus, we are faced with very diverse and original forms of becomings in Japanese architecture recognized by Félix Guattari from the assessment of contemporary Japanese architecture conducted by Betond Bognar (4) such as: a "becoming child" (for example in Takefumi Aida (Guattari, 2015, 78), who designed House like a Die (1973) by appling the traditional okoshie drawing method of Japanese carpenters to achieve "the playful fairy-tale quality" of the object (Bognar, 1985, 246)); a "becoming vegetal" (for example in Mayumi Miyawaki, who constructed his Blue Box in Tokyo (1971) to embrace the tops of some large trees, or in Kijo Rokkaku whose House of Three Roots has 14-metre long raw tree trunks, some of whose roots emerge out of the cement facade (Guattari, 2015, 78); a "becoming animal" (explicitly acknowledged by Team Zoo, a group of young architects, graduates of Waseda University in Tokyo, who, under the influence of their famous mentor Takamasa Yoshizaka, constructed the Domo Celakanto (1975) in the form of a mysterious living organism, a monstrous fish from the sea (Bognar, 1985, 274; Guattari, 2015, 78-9)); a "becoming chapel" (for example in Hiroshi Hara, Shin Takamatsu or Toyokkazu Watanabe, whose Nakauchi House in Nara (1975), like many of Hiroshi Hara's houses in Tokyo, "takes the form of the traditional Japanese storehouse, the kura, but inside turns out to be a tiny Western chapel" (Bognar, 1985, 264)); a "becoming nirvana (5) (for example in Takefumi Aida (Guattari, 2015, 79), who builds the architecture of the PL Institute Kindergarten in Tondobayashi (1973) that "hermetically seals off the inhabitant from the disturbing external environment in order to provide the conditions for moments of silence, as Aida says, in which the individual can recreate himself physically and spiritually" (Aida, in Bognar, 1985, 277); a "becoming non-object" (for example in Hiromi Fuji or Kazuo Shinohara, whose conceptualism seeks to return architecture to zero degree (Guattari, 2015, 79) and to erase its conventional and pragmatic meanings (thus becoming non-objects or negative objects) in order to introduce new meanings based on new existential relations between subject and object, and to put the subject in a position to transform the ordinary self in order to experience a new feeling of existence which brings them close to the traditional Japanese aesthetics inspired by Zen Buddhism (Bognar, 1985, 293); or in Monta Mozuna (Guattari, 2015, 79), whose Antidwelling Box in Kushiro (1971) stands in oppositon to the rational modern mind and thus against modern architecture, embodying the cosmic dimension of architecture - celestial rules, the laws of heaven, terrestrial forces, that he wishes (or pretends) to believe govern human awareness (Bognar, 1985, 268-73)); or a "becoming machine" (for example in Shin Takamatsu, who constructed the Ark: Nishina Dental Clinic in Kyoto (1983) like a "baroque locomotive, simply because of its location adjacent to a railway line and station" (Guattari, 2015, 81), which has an effect of transforming the environment into a kind of vegetative-mechanical landscape, evoking anew the tradition of "decentering of the subject" of Japanese culture by passing from one register to another (Guattari, 2015, 81)).

As Adrian Snodgrass states, architects of the Japanese New Wave, on the one hand, deviate from Western rationalism, while on the other they resort 
6. Steel, reinforced concrete, brick and glass are materials introduced from the West.

Namely, according to Bognar, the first period of the introduction of Western architecture in Japan occured in the second half of the 19th century, with the intention of not importing the "foreign spirit", but rather the new materials, construction methods and building technologies of the West (Bognar, 1985, 80) to the use of Western technology but in a sophisticated way (6) (Snodgrass, 1997, 83). They do not revive handicrafts or the materials and techniques of earlier times, nor do they use technology, like other postmodern architects, to reproduce the superficial forms of the architecture of the past (Snodgrass, 1997, 84). Their aim is "not to reproduce the visible tradition or endorse of any sort of stylistic revivalism, but to preserve the unseen tradition, the spiritual heritage of Japan" (Kurokawa, 1988 in Snodgrass, $1997,84)$. When we say sophisticated technology, the term technology here does not refer to technological equipment and techniques of production but in Heidegger's sense to "the way in which we think about, interpret and view the world within the framework set up by technological rationality" (Snodgrass, 1997, 90). "The greatest danger, says Heidegger, is that posed by the possibility that technological rationality should become the only way of seeing reality; excluding all modes of thinking which lie outside the framework predetermined by technology" (Snodgrass, 1997, 90). The paradigmatic example of exclusivist enframing of thought and praxis would be a scientific method that prescribes in advance what is real, which is defined as something that can be measured and calculated mathematically to show causal relationships (Snodgrass, 1997, 90). Any phenomenon which escapes the network of causal relations would be considered irrational and fictional, and would therefore be excluded from consideration. In the scientific method, things are therefore only present if they have a reason and if they can be calculated, measured, and made into objects for use (Snodgrass, 1997, 90). However, in contrast to the mentioned form of scientific (en)framing of thoughts and actions, technology in Heidegger's sense is not thought of as an application of scientific inventions, nor as the use of machines, equipment and technological processes to manufacture products for use. "It is, rather, the way in which a certain aspect of reality, that which is enframed by technological rationality, is revealed to us" (Snodgrass, 1997, 91).

Namely, the architecture of the Japanese New Wave reveals reality in a different way from Western rationalism. It does not view subjects, society, things and states as independent, isolated entities, traveling from one point to another and remaining inert and unchanged, but as part of a world of transient, changeable and sensory phenomena, a world that dissolves rigid boundaries between external and internal, public and private, rational and intuitive (and other forms of dualistic thinking), which deviates from a priori established forms of thought and emphasizes phenomena rather than a priori relations between phenomena in order to create ambiguity, amorphousness, and a multitude of potentialities. A space in the Japanese New Wave architecture is not viewed as a content of things (as independent of the events), but as an active element in an eventness of things and beings, determined by them but also determining for them.

In such a theoretical framework, we can position the work of Japanese architect Sou Fujimoto. Namely, this study will show that Sou Fujimoto's architecture can be supported by post-structuralist theory, primarily by Deleuze's and Guattari's philosophy of becoming on the one hand, and the Japanese tradition of non-dualistic thinking on the other. That is, the study argues that, using sophisticated technology, Fujimoto departs from Western rationalism and structuralist theoretical thought in Western philosophy, and interprets the Japanese tradition of non-dualistic thinking (primarily of being in-between architecture and nature) in an original way, building an architecture of creative becomings, and, beyond that, new forms of living. 


\section{SOU FUJIMOTO}

Sou Fujimoto, was born in 1971 in Hokkaido (Japan), but he moved to Tokyo to study architecture. Having moved to Tokyo, Fujimoto did not experience this city as foreign and unpleasant. Despite the chaotic, Fujimoto found similarities that bound him to his home town, the city filled with nature (Fujimoto, 2018). As Fujimoto (2018) says:

“[...] after learning architecture and thinking about space and urban situations I realized something behind those kind of different appearances. [...] We could see some kind of similar structures or similar scales are there. In the forest, [...] you are surrounded by many small leaves, and branches are surrounding you to create human scales and cozy, protected feelings. And at the same time, of course, it's not closed areas, it's like an open field. You can choose your own way to move around. And in Tokyo, [...] you will be surrounded by such small, artificial, messy things. Even the electricity cables are like softly covering you to protect yourself, to create such a [...] human scale. And then of course it's an open field. You can choose your own way. So [...], it looks so different. But the structures behind your experiences are almost the same. And that was quite an interesting moment to find out such different things could have similar systems or structures behind it. And then we treat both of them, so different things as equals. And then we can handle both of them as kind of like, exchange them, or mix them, or whatever we like. And then the relationship between nature and architecture is completely changed in my mind. [...] it is quite interesting to rethink what we know. Because we can find out something new, reinterpretations, or a new understanding from that."

Finding inspiration in nature, primarily in the tradition of Japanese culture deeply rooted in a unique relationship with nature, which, unlike Western culture, is not aimed at conquering nature, but in living in harmony with it (7), Fujimoto discovered similarities between structures of nature and structures of architecture which lead him to a different understanding and rethinking of architecture. Namely, his approach to architectural design is not based on direct introduction of elements of nature into the interior of architecture, nor on the iconic appropriation of elements of nature, but rather on a diffractive reading and translation of the structures of nature into the structures, sense, significance and meaning of architecture, in other words an affirmative, creative reading of essential insights of the structures of nature through the structures of architecture and thus a "reworking" of the traditional beliefs that structure these insights.

Inspired by diffraction (conditionally speaking) as an optical phenomenon, the American feminist thinker Karen Barad develops diffractive methodology in her book Meeting the Universe Halfway: Quantum Physics and the Entanglement of Matter and Meaning (2007) in opposition to the reflective

7. As Bognar states: “Traditionally Japanese culture evolved from and is deeply rooted in the intense, uniquely intimate relationship of the Japanese to nature, which itself reveals basic differences between Eastern and Western mentalities. The Westerner tends to have a superior-inferior relationship with nature, while the Oriental thinks of himself as a coordinate, equivalent to and identifying with nature. Modern Western culture, along with its predecessors, the ancient Egyptian, Greek, and Roman cultures, openly declares its intention of conquering nature. By contrast, the Oriental wants to live in harmony with it. In other words, the traditional Japanese attitude is characterized by a strong impulse to merge with, rather than to overcome, nature" (Bognar, 1985, 23). methodological approach. Diffraction is a counterpoint to reflection: "both are optical phenomena, but whereas the metaphor of reflection reflects the themes of mirroring and sameness, diffraction is marked by patterns of difference" (Haraway, 1997 in Barad, 2007, 71). "A diffraction pattern does not map where differences appear, but rather maps where the effect of differences appear" (Haraway, 1992 in Barad, 2007, 72). According to Barad, the reflective methodological approach is a representative approach, one that is based on the belief that words, concepts and ideas accurately reflect or mirror the things to which they refer, while diffractive methodological approach is non-representative, that is, it is based on opinions about different (for example, social and natural) practices in a performative rather than a representationalist mode (Barad, 2007, 86-8). It is therefore not a matter of reading two different disciplines, or two different texts or 
"ways of thinking" against each other, positioning one in a static geometric relation to the other, or setting up one as the unmovable and unyielding foil for the other, nor is it a bidirectional approach that adds the results of what happens when each takes a turn at playing the foil (Barad, 2007, 92). Rather, it is a conversation of different (inter)disciplinary practices with one another, engaging the aspects of each in dynamic relationality to the other, being attentive to the iterative production of boundaries, the material-discursive nature of boundary-drawing practices, and, one step further, thinking about insights from different disciplines through one another in ways that help to illuminate differences as they emerge and noticing the reasons why they matter (Barad, 2007, 92-3). It is therefore a matter of reading insights, concepts and ideas, of different disciplines through each other, and thus reworking the tradition of thoughts that structure these insights, concepts and ideas, paying attention at the same time to the (changeable) nature of the frameworks or apparatuses through which we perceive these differences. It is not just about discovering the differences, but about the production and reconfiguration of differences.

How does Fujimoto, inspired by the Japanese tradition of non-dualistic thinking, translate the structures and concepts of nature through the structures and concepts of architecture, and how does he redefine the traditions of thought from which these concepts emerge? How does he move away from structuralist theoretical thought, building different space-time concepts, concepts of "being in-between"? How can his space/ architecture of "being in-between" be understood in the language of Deleuze's and Guattari's philosophy of becoming? What is the significance of this approach to architecture, and the significance of his architecture to society, art and culture? How can Fujimoto's architecture be read as a material-discursive practice or apparatus of social production of meaning? I will try to explain this through analysis and interpretation of five key examples of Fujimoto's architectural work: Serpentine Gallery Pavilion (2013, London, UK), House NA (2011, Tokyo, Japan), Musashino Art University Museum \& Library (2010, Tokyo), House N (2008, Tokyo), and L'Arbre Blanc (2019, Montpellier, France), essential to the understanding of Fujimoto's innovative approach to the Japanese tradition of non-dualistic thinking and deviation from structuralist theoretical thought.

\section{FUJIMOTO'S DEVIATION FROM STRUCTURALIST THEORETICAL THOUGHT}

It is possible to single out several key elements that separate Fujimoto's architecture from structuralist theoretical thought: (i) understanding the structure as an open concept; (ii) understanding the sign and meaning of architecture as a process (architecture as a material-discursive practice of social production of meaning); (iii) placing emphasis on phenomena rather than a priori relations among phenomena; (iv) critique of Cartesian dualistic thinking; and (v) taking into account the context in which the object appears.

(i) Fujimoto does not see a structure of an architectural space in a structuralist way, that is as a closed concept, one in which the whole emerges from internal formal connections between the parts of architecture (as language) producing a relatively coherent meaning. Elements of the structure for Fujimoto are not dependent and semantically determined by the entire structural system, and individual units have no meaning by virtue of their relationship to another unit. Structure of architectural space 
8. The term "Whole" is used in this study in Deleuzian context. In this sense, the "Whole" does not refer to a closed set, but to a set of sets, a frame of frames, which does not close in itself, but on the contrary - connects each set with everything else. The "Whole" is a deterritorialization of sets.

9. Karen Barad introduces neologism intraaction as a key concept in understanding mutual constitution of different entities and entangled agencies. "In contrast to the usual interaction, which assumes that there are separate individual agencies that precede their interaction, the notion of intra-action recognizes that distinct agencies do not precede, but rather emerge through, their intra-action" (Barad, 2007, 33). In other words, "distinct agencies are only distinct in relational, not an absolute, sense, that is, agencies are only distinct in relation to their mutual entanglement; they don't exist as individual elements" (Barad, 2007, 33).

10. In the line with the understanding the notion of weak thought developed by the Italian philosopher Gianni Vattimo in the 1980s, which (less as a school of thought, but more as an intellectual approach) focuses on a critique of universalist pretensions based on the hegemony of reason, weak architecture refers to one that is not founded and thought in a metaphysical and Platonic way, as a stable structure based on the realm of the immutable; nor as one based on a weakening relationship with the origin. It does not break with the origin (tradition) but offers an attempt to rethink the origin/ tradition by rewriting, testing and redefining its traces. Weak architecture, therefore, is not that architecture which gives up its tasks because it is supposedly no longer able to deal with them, but one that is ready to carry out philosophical reflections outside the "eternal structures" explained by rational argumentations. It is a kind of deviation from the Western rationalist opinion of modernity (On the weak thought see: Stevanović, 2015). is for Fujimoto a relation of elements and relations (which are established by the architect as well as the occupants of the space, but also by the wider social, urban and natural environment in which the object appears). Analogous to the Deleuzean conceptualization of structure, we could say that Fujimoto's structure is seen as a set of elements and relations that are separate but nevertheless connected in such a fundamental way that any moment of the structure cannot acquire an identity outside this interrelation. Elements of the structure thus exist only to the extent that they are structured by relations, and relations in turn have no reality independently of these activities of related terms (Crocker, 2001 in Bojanović ed., 2011, 180). "In short, elements do not have an identity independently of relationships that connect them to the system, and the relationships themselves are dependent on their actualization within the term" (Crocker, 2001 in Bojanović ed., 2011, 180). The element and relations of a structure reciprocally determine each other and the identity they acquire is never finite and closed toward the transformative effects of the structure as a whole (Crocker, 2001 in Bojanović ed., 2011, 180). "The structure would then be considered as a function of elements and relations" (Crocker, 2001 in Bojanovć ed., 2011, 180). However, the structure is here seen as the term for an open whole in which elements and relations participate, that is, as the relation itself. In other words, the structure (or the Whole (8)) of Fujimoto's space of architecture is understood as a relation of elements and relations.

Take, for example, Fujimoto's House NA (realized in 2011 in Tokyo). The structure of the space of this building is conceived as an open Whole. The space is divided into several space units located under one roof, or as Fujimoto states, we could say that here we do not have only rooms, but one room (Fujimoto, 2011), or in the language of Deleuze and Barad that we have many rooms defined by intensive (rather than extensive) boundaries that enter into intra-active (9) relationships and communication. Namely, this spatial concept was derived from the understanding and reading of Toyo Ito's architecture of Sendai Mediatheque (designed in 1995 in Sendai, Japan) (Fujimoto, 2011), in which pillars were not conceived as closed, giant concrete tubes (as, for example, in Kenzo Tange's Yamanashi Press and Broadcasting Center (1966)), but transformed by their perforated, curved structure into an open space of communication that takes place with other surrounding spatial units. Inspired by this idea, Fujimoto transforms the floor surface and the wall into the (layers of) space (Fujimoto, 2011). House NA, is built of multiple floors (a total of 20 floors, some of them measuring $1.4 \times 2.5 \mathrm{~m}$, while the largest is $2.5 \times 2.5 \mathrm{~m})$, multiple layers of space randomly arranged within a single field (hinting at the traditional idea of denying functionalism in the name of multifunctionality achieved through the diverse use of tatami floors). In this house we do not have conventional floors (delimited by full squarish walls), conventional walls and stairs. Each floor becomes a multifunctional field that enters into relations with the other floors. Among them, there are no clearly defined, closed, extensive borders (conventional walls), but imaginary, invisible borders as intensive concepts. It is a kind of weak architecture (10), that is not, according to Fujimoto, made "from an overall order, but from the relationships between each of the parts" (Fujimoto, 2008, 9). From this relationship, "an order can be made that incorporates uncertainty or disorder" (Fujimoto, 2008, 9). People are thus invited to respond as they wish to these layers of space, to their density and transparency, to their acentric distribution. The floor thus becomes at different moments a shelf, a sofa, or a chair (Fujimoto, 2011). 
(ii) By understanding architecture as a discourse rather than a language or a self-referential linguistic system, Fujimoto breaks the established syntactic and pragmatic relations between elements of architecture, building an architecture that enters into intra-active communication with the subject, society, urban and natural environment. His architecture is not based on formal relations and combinations of elements independent of psychological, social and other contexts, in other words, it is not conceived as a corpus of purely formal inert sequences of elements, but rather as an open process that is a (signifying) practice of production of meaning. Namely, different activities and different uses of space (material practices) of Fujimoto's architecture, exemplified in House NA, continually change the meaning of this space (Fujimoto, 2018). As we do not have clear definitions of space and elements of space, nor clear divisions between units of space, everywhere there are only blurring effects of architecture, furniture and landscape. Users thus enter into intra-action with different indoor, spatial units as well as external environments. In accordance with the reactions of users of the space, new functions appear and others disappear. Each thing depends on the relations between the body of the subject/user of space (material-discursive practices), space of architecture and, urban and natural environment, which is very different from the a priori system of structuralist theoretical thinking, that is, the a priori imposition of universal sense and meaning.

(iii) By focusing on phenomena rather than the a priori relations between phenomena, Fujimoto emphasises an interest in the essences of a process (specifically, for the matter of an object but also material, social relations), rather than the essences of the thing/object. How can we understand this? "The essence of thing is that which explains its identity, that is, those fundamental traits without which an object would not be what it is" (De Landa, 2002, 9). It is related to the essentialist view of the world versus the essence of the process that is related to the morphogenetic-anti-essentialist view of the world. Namely, while an essentialist account looks for the commonalities of, for example, an animal species, that remain eternal and immutable over time, and that can be used as a basis for explaining the identity of a particular species, as well as the fact that particular members of the species resemble each other, the morphogenetic account is interested in a wider set of circumstances that allows a particular species to appear (De Landa, 2002, 9). In other words, while an essentialist account may rely on factors that transcend the realm of matter, things and energy (eternal archetypes, for instance, in architecture), a morphogenetic account gets rid of all transcendent factors and use exclusively immanent generating resources of form (De Landa, 2002, 10).

In the context of Fujimoto's architecture, we could say that Fujimoto is interested more in the morphogenetic processes than the essentialist features of an object, in the formation rather than the formed, that is, not only in the static, immutable properties of the geometry of the object, but rather in the ways in which these properties change over time and provoke unexpected reaction in users. Through the creative use of Euclidean geometry, Fujimoto reveals its hidden potentials (Fujimoto, 2018), capturing it in the act of becoming non-Euclidean. Take, for example, the Serpentine Gallery Pavilion (built in London in 2013). The pavilion occupies about 357 square meters of land in front of the Serpentine Gallery. Its lattice structure is constructed of $20 \mathrm{~mm}$ thick steel columns arranged in a Euclidean grid, building at first glance a three-dimensional Euclidean grid space. However, as one moves through this space, the observer faces 
different densities and transparencies of this structure (Fujimoto, 2018), experiencing it as a four-dimensional or $\mathrm{n}$-dimensional continuum, as a static space captured in the act of becoming dynamic, analogous to the idea of the cloud, or, one step further, as a field in a continuous process of becoming ("becoming non-metric" of metric, "becoming tactile/haptic" of optic, "becoming soft" of solid, "becoming intensive" of extensive, "becoming transparent" of opaque etc.), thus emphasizing not the complexity of the state of change of this object (for example, the fact that the grid structure can be continued vertically or horizontally along the $\mathrm{x}, \mathrm{y}$ and $\mathrm{z}$ axes while retaining the structure of the Euclidean grid) but the complexity of the modeling of space (playing between simplicity and complexity, transparency and opacity, solid and soft, etc.), which can be experienced by moving through this space, Fujimoto emphasizes the nature of $\mathrm{n}$-dimensional space, that is, the nature of multiplicity and consequently a variable identity (of the contemporary concept of subject, society, architecture) which is guided by singularities and changes, instead of by eternal, fixed and unchangeable essences.

(iv) Criticizing the dualistic conception of Cartesian traditionalism, the binary pairs in Fujimoto's architecture are not placed in juxtaposition excluding each other, but, on the contrary, in a relationship of superimposition, simultaneously existing in the same space and mutually transforming each other. Through the game of intra-active communication, for example, the solid, extensive, static, steel, Cartesian grid of the Serpentine Gallery Pavilion is caught in the act of becoming a soft, intensive, mobile grid; the interior/internal space of House $\mathrm{N}$ is caught in the act of becoming exterior/external, or the openness (exposure to external influences of nature) of this home is caught in the act of becoming protection; the floor in House NA is caught in the act of becoming furniture; strategic movement through the Musashino Art University Library, which depends on reason and view, is caught in the act of becoming tactical and intuitive, etc. This is a special kind of space of communication between incompatible events, for example a space of toleration.

(v) By carefully developing his ideas, taking into account the context of the object, Fujimoto builds an architecture that becomes open to the natural, cultural and urban environment or context. The environment is not something that is neglected, but rather an element by which one can become engaged in intra-active communication. Take, for example, House $\mathrm{N}$. The building is based on the idea of "a box in a box in a box" (Fujimoto, 2018), as a kind of interpretation of "the Japanese idea of space layering to extreme" (Bognar, 1985, 276), where each box is perforated with frames of different sizes. The frames of the largest and smallest box are left open, while the frames of the middle box are closed with glass (Fujimoto, 2011). Through these frames and framing the communication is established with both the natural and the urban environment, with the processes of nature but also with the processes of the society and culture in which the object is located. The architecture thus becomes defined, transformed and modified by these contexts, but also for them determinative. Let us now focus on this communication between nature and architecture, for example on the play of catching the architecture in the act of "becoming nature". 


\section{THE “BECOMING NATURE” OF FUJIMOTO'S ARCHITECTURE}

It is possible to single out several features of Fujimoto's architecture that capture it in the act of "becoming nature": (i) the indirect presence of the structures and effects of nature; (ii) a high degree of symmetry, and (iii) acts of deterritorialization and reterritorialization.

(i) Take, for example, the Musashino Art University Museum \& Library (built in Tokyo, in 2010). The building is conceived on the idea of a large wall $6000 \mathrm{~m}$ long filled with shelves, in the form of a continuous, open spiral "without beginning and end". This spiral wall is (seemingly) randomly perforated with large openings - frames. These openings are not radially, symmetrically or centrally arranged, but randomly scattered along a spiral wall, offering "two" possible ways of moving through the space: one that follows the flow of the spiral and systematically arranged books (along the spiral wall), and the other meandering, wandering, allowing nomadic movement through the openings and spaces of the library, analogous to the idea of wandering through a forest (Fujimoto, 2018). The emphasis is thus placed on intuition and imagination rather than physical involvement, which depends on reason and view, on the accidental and unpredictable rather than the planned and predictable. Randomly arranged openings do not offer all-seeing, monocentric, perspective space, but displaced, infinite points and horizons that indicate new, hidden spaces (Fujimoto, 2018). Like the experience of moving through the forest, the emphasis is placed on an intimate relationship with the parts, while the whole remains unattainable and can only be evoked and perceived in the imagination of the observer. With this type of spatial experience the "path" becomes more important than the arrival, for example the journey "through" more important than the final destination or goal (in accordance with the traditional Japanese-Hinto and Buddhist belief in the importance of travel as a process rather than a final destination). Each node of the path marks both the point of arrival and the point of departure, that is, the point of development, growth and process. The library of the Musashino Art University is thus deprived of some real, usually expected climax or center. Instead of the center (a central element or object in space) we are faced with a gaping hole - the atrium - or emptiness.

Or consider, for example, the already mentioned Serpentine Gallery Pavilion. The thin, white, steel pillars arranged in a Cartesian grid offer a solid, metric, extensive space. However, moving through this pavilion, the visitor is confronted with different transparencies and densities of the space (Fujimoto, 2018), perceiving it as a soft, non-metric, intensive field, analogous to the idea of a cloud. House N, also offers an interesting blurring of the boundaries between architecture and nature. Getting into an intra-active communication with light and shadow, the white walls of House $\mathrm{N}$ become, at moments, confused with the whiteness of the surrounding clouds seen through the object's frames (Fujimoto, 2018), thus offering a play between opaque and transparent, closeness and remoteness, bounded and infinite, closed and open, hard and soft, immovable and movable.

(ii) Although based on Euclidean geometry, Fujimoto's spaces possess a high degree of internal symmetries, that is, spaces of equal distances from future and past events, but also from different equivalent "geometric" figures of space. For example, in House NA, the floors are not distributed around a center, but randomly scattered, creating a multicenter field that allows the simultaneous existence of different social events and their 
mutual intra-action, without knowing which of them happens before and which after. In terms of physics, it is a multicentered field, filled with many singular points, that is, a field in a continuous process of becoming. By breaking down the usual syntagmatic and paradigmatic relationships between elements of architecture (for example, replacing a chair and a table with a floor), Fujimoto builds multifunctional spaces of unpredictable social, perceptual directions and connections. House $\mathrm{N}$ offers a slightly different form of internal symmetries. Based on the idea of "a box in a box in a box", that is on fractal geometry, Fujimoto offers a fractal set of frames, where frames formed in smaller scale contain the characteristics of frames formed on a larger scale but never repeat the same pattern. It is a space based on a self-similarity, iteration, or a recursive symmetry, whose many examples can be found in nature. L'Arbre Blanc, an apartment complex built in 2019 in Montpellier (France), is another example of an architectural space which possesses a high degree of symmetry. Based on the idea of dropped console terraces ( $8 \mathrm{~m}$ long and $6 \mathrm{~m}$ wide), scattered randomly around the central core of the vertical object, it offers a structure that is closer to the a-hierarchy, a-causality, unpredictable connectivity, multiplicity and heterogeneity of a rhizome, rather than the hierarchy, cause and effect connectivity and homogeneity of a tree (of a technological rationalism).

(iii) The walls of Fujimoto's architecture in, for example, House $\mathrm{N}$ do not have only a territorializing function. The frames, windows and walls here do not only separate the territory in general; they also allow deterritorialization, that is, a selective opening toward the urban and natural environment, and re-territorialization, by entering into intraactive communication with the environment through which the interior architecture of the home is shaped (by the effects of light and shadow on a formal level, but also on a material level in which relations between people are interwoven with relations of the urban environment) as well as the "interior space of the urban environment" (by understanding the part of the outer box of this object, inspired by the traditional Japanese concept of engawe - a veranda that mediates between the inner and outer space - as a kind of extension of the urban space/environment). Nature is therefore not treated by Fujimoto as something that exists somewhere "there" (which would correspond to the Western rationalist approach to nature). Fujimoto's walls are not filled with still life paintings, but, on the contrary, imbued with frames, they capture nature in the act of becoming an artistic painting.

This is a creative translation of the Japanese tradition of non-dualistic thinking on the relation between architecture and nature, that is, a diffractive reading of the structures of nature through the structures of architecture. Fujimoto's approach to the structures of nature (in the above mentioned examples) is therefore not based on mimesis, mirroring, iconic translation, nor on direct introduction of elements of nature into the interior of architecture, but on the creative translation of seemingly unrelated structures, both natural (for example, the idea of a "cloud" in the Serpentine Gallery Pavilion) and artificial (the steel Euclidean grid), which makes possible reworking of the concepts that structure these "insights" and the tradition of thought from which these concepts emerge. In this way Fujimoto "discovers the hidden potentials of Euclidean grid" (Fujimoto, 2018), and reworks the tradition of thought of Euclidean geometry, showing that the non-Euclidean effect of space can be achieved by Euclidean means, or in other words, that energetic, dynamic and chaotic 
structures and relations between people, architecture and nature can be achieved through repetitions of the same spatial units and the apparently subtle order of the structural elements of architecture (Fujimoto, 2018).

\section{FUJIMOTO AND THE ARCHTECTURE OF NEW FORMS OF LIVING}

The dominant intra-activity of Fujimoto's architecture takes place not only in the relationship between architecture and the natural environment, but also in the relationships between subject and subject; subject and object; subject and social, cultural, urban environment; subject and nature. Namely, interested in the formation rather than the formed of architecture, Fujimoto plays with Euclidean architecture, subject and the context/ environment in an interesting way. He seeks to create forms from material processes, rather than impose form on matter, that is, from the process of intra-activity of subject, object, society and natural and urban environment.

At the level of the category of the subject, if we define the form as a reflection in ourselves, as a relationship to self, that is, as identity or One, and the matter as a reflection in the Other, as a relationship to another, that is as a difference or Multitude, we could say that Fujimoto is interested in the concept of intra-subjectivity, or the question of ' $I$ ' that develops itself from the process of materiality, that is, intra-activity with Other. ' $\mathrm{I}$ ' is not something that is a priori imposed (such as in the concepts of modernist architecture of mass production of early capitalism), but something that arises from an intra-active relationship with the Other. Identity (form) is not imposed here on material processes (matter) but derives from material processes (materialization of matter). In this way, Fujimoto builds spaces for chance and event, spaces which are not introspective and contemplative, but which open us toward feelings, inside and outside of us. They open our pores to the Other, allowing the world/nature/society to enter into us, but also allowing us to enter into the world/nature/society. In this way they make us ready to receive the Other, but also, to give (that Other). In this context, Fujimoto's "spaces in between" can be seen as operative/performative rather than representative concepts that are not based on imitations or mimesis of nature-based structures, but on their creative "translation".

Using sophisticated technology, primarily enabling intra-active communication with the Other, Fujimoto's architecture thus offers new forms of living that cannot be thought of and conceptualized in the frameworks of an ontology of One and the traditional Western image of thought (the thought of the classic ontology that moves in the framework of analogies, similarities, fixed identities and the essence of things), but in the frameworks of an ontology of identity and difference, One and Multiple, the essence of processes, such as becomings. This architecture is not given, but mutually constituted with the society and the urban and natural environment, becoming thus an agent of change that participates in the restructuring and thus regulation of everyday life, taking an active role in the unwinding of events. It is not an instrument in which the "world" takes place, or in which "the object of the world" is located, but an integral part of the phenomenon of the world which helps to constitute them. Furthermore, it is not a neutral viewing device or a Euclidean frame of reference that allows us to specify the social locations of individual users or trace the trajectories of identity formation, but rather it can be seen as an operative, material-discursive apparatus of social production of a multitude of potentialities, sense and meaning, new sensations and sense knowledge. 
11. Fujimoto's spaces are political in Jacques Rancier's sense of meaning, because they are realized as a distance in relation to the usual everyday forms of a human sensory experience, a being (living in the space of architecture) and an (rationalist) understanding, because they manage to open itself as a gap and a distance in relation to the status quo, and because they reconfigure the sensual and the cognitive by introducing the new subjects and objects that make visible that what was until then not possible. (For understanding the political space in Jacques Rancier see: Matejić, in Suvaković, 2017, 269-79.)
This is a special kind of free political space (11), which enables not only the emancipation of architecture (by releasing architecture from a priori forms of presentation, a priori sense and meaning, limited uses, functions and conventions), but also the emancipation of the subject, society and culture through architecture (by a reconfiguration of human sense and feelings for Other, for nature and the urban and architectural environment). In other words, as Mohsen Mostafavi observes, his architecture has a "capacity to redefine social relations and not to dictate them" (Mostafavi in Fujimoto, 2011), that is it does not impose a priori, pre-defined relations, but moves the subject (his/her sensory-motor apparatus) on an act. It does not teach us about anything special except our own, immanent, creative sources and forms of existence. And, in the moment of the encounter with such existence the emancipatory turn is reflected, that is, the emancipatory significance, sense and value of Fujimoto's architecture for the subject, culture, society and art.

\section{ACKNOWLEDGMENTS}

The author wishes to thank the two anonymous reviewers for their insigthful comments and Dr. Philip Hepburn for his help related to the translation of her text into English.

\section{BIBLIOGRAPHY}

BARAD, K. (2007) Meeting the Universe Halfway_Quantum Physics and the Entanglement of Matter and Meaning, Duke University Press, Durham and London.

BOGNAR, B. (1985) Contemporary Japanese Architecture: Its Development and Challenge, Van Nostrand Reinhold Company, New York.

BROTT, S. (2011) Architecture for a Free Subjectivity: Deleuze and Guattari at the Horizon of the Real, Ashgate, Farnham-Burlington.

CROCKER, S. (2001) U intervalu: O Delezovom preokretu vremena i kretanja, Slike Mišljenja Žila Deleza, Images of Thought by Gilles Deleuze, trans. K. Bojanović, ed. Kristina Bojanović, Društvo filozofa Crne Gore, Nikšić, 169-90.

De LANDA, M. (2002) Intensive science E virtual philosophy, Continuum, London and New York.

FUJIMOTO, S. (2018) Between Nature and Architecture. [https://www.gsd. harvard.edu/event/sou-fujimoto/] Access Date (11.01.2019).

FUJIMOTO, S. (2011) Primitive Future. [https://www.youtube.com/ watch?v=MGLO-GPYfbg] Harvard GSD, Access Date (11.01.2019).

FUJIMOTO, S. (2008) Sou Fujimoto: Primitive Future, Inax, Tokyo.

GUATTARI, F. (2015) The Architectural Machines of Shin Takamatsu, Machinic Eros: Writings on Japan by Felix Guattari, eds. G. Genosko and J. Hetrick, Univocal, Minneapolis; 77-6.

MATEJIĆ, B. (2017) Politički prostor, Prolegomena za pojmovnik estetike, filozofije i teorije arhitekture, ed. M. Šuvaković, Orion Art, Beograd; 269-79.

SNODRGASS, A. (1997) Translating Tradition: Technology, Heidegger's 'Letting-be', and Japanese New Wave Architecture, Architectural Theory Review, 2(2), 83-104. 
Alındı: 09.11.2019; Son Metin: 17.05.2021

Anahtar Sözcükler: (Post-)Yapısalcılık; oluş; kırınım okuma; aradaki boşluklar; Sou Fujimoto'nun mimarisi.
STAGOLL C. (2005) Becoming in The Deleuze Dictionary, ed. A. Parr, Edinburgh University Press, Edinburgh, 21-2.

STEVANOVIĆ, V. (2015) Đani Vatimo, Orion Art - FMK, Beograd.

\section{YARATICI OLUŞUMLAR MIMARİSI: SOU FUJIMOTO}

Bu yazı, Sou Fujimoto'nun yaratıcı oluşumlar mimarisinin, özellikle mimarlığın doğa oluşuna örnek olan mimari çalışmasının bir araştırmasıdır. Çalışmanın ana hipotezleri; (i) Sou Fujimoto'nun mimarisinin bir yanda Post-yapısalcı teori, özellikle Gilles Deleuze ve Felix Guattari'nin çalışmaları, diğer yanda ise Japon ikili olmayan düşünce geleneği tarafından desteklenebileceğidir; (ii) Fujimoto'nun doğadan ilham alan yaratıcı mimari formlarının, yapılarına yansıtıcı bir yaklaşımın sonucu değil, mimari yapılar aracılığıyla doğa yapılarının kırınımsal okumasının sonucu olduğudur. Çalışma, Fujimoto'nun mimarisinin beş önemli örneğini analiz etmektedir: Serpentine Gallery Pavilion, House NA, House N, Musashino Sanat Üniversitesi Müzesi ve Kütüphanesi ve L'Arbre Blanc. Ve Sou Fujimoto'nun mimari tasarıma yenilikçi yaklaşımının yaratıcı oluşumlardan oluşan bir mimari inşa ettiği sonucuna varmaktadır. Bu yaratıcı yaklaşımlardan oluşan mimari sadece mimarlığın değil, aynı zamanda öznenin, toplumun ve kültürün de mimarlık aracılığıyla özgürleştiği yeni yaşam biçimleridir. Teorik bağlamda, çalışma öncelikle Gilles Deleuze, Félix Guattari, Karen Barad ve Botond Bognar'ın araştırmalarına atıfta bulunmaktadır.

\section{ARCHITECTURE OF CREATIVE BECOMINGS: SOU FUJIMOTO}

This study is an investigation of Sou Fujimoto's architectural work as an example of architecture of creative becomings, above all the becoming nature of architecture. The main hypotheses of the study are: (i) that Sou Fujimoto's architecture can be supported on the one hand by poststructuralist theory, primarily by Gilles Deleuze's and Felix Guattari's studies, and on the other by the Japanese tradition of non-dualistic thinking; and (ii) that Fujimoto's creative architectural forms inspired by nature are not the result of a reflective approach to their structures, but diffractive reading of the structures of nature through the structures of architecture. The study analyses five key examples of Fujimoto's architecture: the Serpentine Gallery Pavilion, House NA, House N, Musashino Art University Museum \& Library and L'Arbre Blanc, and concludes that Sou Fujimoto's innovative approach to architectural design builds an architecture of creative becomings, that is new forms of living, performing not only the emancipation of architecture but also the emancipation of the subject, society and culture through architecture. In a theoretical context, the study primarily refers to the research of Gilles Deleuze, Félix Guattari, Karen Barad and Botond Bognar.

ŽELJKA PJEŠIVAC; M.Arch., M.A., PhD.

Received her M.Arch. from University of Novi Sad, Faculty of Technical Sciences, Department of Architecture and Urbanism, M.A. degree in scene design from University of Arts in Belgrade, and Ph.D. degree in theory of arts and media from University of Arts in Belgrade, Serbia. Research interests include architectural design, history and theory of architecture and arts, philosophy of space and time, cultural analysis and cultural heritage studies. 
